\title{
The mRNA expression of pro- and anti-inflammatory cytokines in $T$ regulatory cells in children with type 1 diabetes
}

\author{
Włodzimierz Luczyński ${ }^{1}$, Anna Stasiak-Barmuta ${ }^{2}$, Agnieszka Juchniewicz ${ }^{3}$, Natalia \\ Wawrusiewicz-Kurylonek ${ }^{4}$, Elżbieta Iłendo ${ }^{5}$, Justyna Kos ${ }^{6}$, Adam Krętowski ${ }^{4}$, \\ Maria Górska ${ }^{4}$, Lech Chyczewski ${ }^{7}$, Artur Bossowski ${ }^{1}$
}

\author{
${ }^{1}$ Department of Pediatrics, Endocrinology, Diabetology with Cardiology Division, \\ ${ }^{2}$ Department of Clinical Immunology, ${ }^{3}$ Department of Thoracic Surgery, \\ ${ }^{4}$ Department of Endocrinology, Diabetology and Internal Medicine, ${ }^{5}$ Department of Cytogenetics, \\ ${ }^{6}$ Department of Dentistry, ${ }^{7}$ Department of Clinical Molecular Biology \\ Medical University of Białystok, Białystok, Poland
}

\begin{abstract}
Type 1 diabetes mellitus (T1DM) is caused by the autoimmune-mediated destruction of insulin-producing beta cells in the pancreas. T regulatory cells (Tregs) represent an active mechanism of suppressing autoreactive T cells that escape central tolerance. The aim of our study was to test the hypothesis that T regulatory cells express pro- and anti-inflammatory cytokines, elements of cytotoxicity and OX40/4-1BB molecules. The examined group consisted of 50 children with T1DM. Fifty two healthy individuals (control group) were enrolled into the study. A flow cytometric analysis of T-cell subpopulations was performed using the following markers: anti-CD3, anti-CD4, anti-CD25, anti-CD127, anti-CD134 and antiCD137. Concurrently with the flow cytometric assessment of Tregs we separated CD4+CD25+CD127dim/- cells for further mRNA analysis. mRNA levels for transcription factor FoxP3, pro- and anti-inflammatory cytokines (interferon gamma, interleukin-2, interleukin-4, interleukin-10, transforming growth factor $\beta 1$ and tumor necrosis factor $\alpha$ ), activatory molecules (OX40, 4-1BB) and elements of cytotoxicity (granzyme B, perforin 1) were determined by real-time PCR technique. We found no alterations in the frequency of $\mathrm{CD} 4{ }^{+} \mathrm{CD} 25^{\text {high }} \mathrm{CD} 127^{\text {low }}$ cells between diabetic and control children. Treg cells expressed mRNA for pro- and anti-inflammatory cytokines. Lower OX40 and higher 4-1BB mRNA but not protein levels in Treg cells in diabetic patients compared to the healthy children were noted. Our observations confirm the presence of mRNA for pro- and anti-inflammatory cytokines in $\mathrm{CD} 4{ }^{+} \mathrm{CD} 25^{+} \mathrm{CD} 127^{\mathrm{dim} /-}$ cells in the peripheral blood of children with T1DM. Further studies with the goal of developing new strategies to potentiate Treg function in autoimmune diseases are warranted.
\end{abstract}

Key words: 4-1BB, autoimmunity, granzyme, OX40, perforin, scurfin, T lymphocytes

\section{Introduction}

Type 1 diabetes mellitus (T1DM) is caused by the autoimmune-mediated destruction of insulin-producing beta cells in the pancreas. Presently in Europe, children with T1DM in Europe are treated with insulin which leads to the good metabolic control, but unfortunately there is no causative cure for this disease.

Correspondence: W. Łuczyński, Dept. of Pediatrics, Endocrinology, Diabetology with Cardiology Division, Medical University of Białystok, Waszyngtona Str. 17, 15-274, Poland; tel./fax.:(+4885) 7450-730, e-mal: w.luczynski@wp.pl
During the last decade there has been a great progress in understanding the role of peripheral tolerance breakdown in the pathogenesis of autoimmune diseases. The most important immunologic defects that occur in T1DM are related to T lymphocytes. In recent years, there has been a great deal of interest in developing immunotherapy approaches to treat T1DM. Those approaches should include preventing or suppressing

Abbreviations: APC - antigen presenting cells, IFN - interferon, IL - interleukin, NOD mouse - non-obese diabetic mouse,

T1DM - type 1 diabetes mellitus, TNF - tumor necrosis factor,

Tregs $-\mathrm{T}$ regulatory cells 
autoimmune reaction by influencing $\mathrm{T}$ lymphocytes. Autoreactive $\mathrm{T}$ cells are normally present in most individuals and $\mathrm{T}$ regulatory cells (Tregs) represent an active mechanism of suppressing autoreactive $\mathrm{T}$ cells that escape central tolerance. The critical role for regulatory $T$ cells (Treg) in suppressing autoimmune pathology is now well recognised [1]. However, the extent to which defects in regulation can be blamed for the onset of diseases like type 1 diabetes is not clear. Since their discovery, extensive research has focused on phenotype, activation mechanisms and suppressive function of Tregs, but the precise molecular basis of these processes in still not known. It also takes a lot of effort to identify the unique molecules expressed only on T regulatory cells. In addition to CD25 and FoxP3, other markers given consideration are: CD103, OX40, 4-1BB, GITR, CTLA-4, PD1 and neuropilin-1 (reviewed in [2]). None of these cell surface markers appear to be definitive. Transcription factor FoxP3 represents a classical Treg cells marker. Two recent reports found a strong correlation between FoxP3 expression and down-regulation of IL-7 receptor (CD127) [3,4]. For functional studies the $\mathrm{CD} 4{ }^{+} \mathrm{CD} 25^{\text {high }} \mathrm{CD} 127^{\text {low }}$ cells are considered as $\mathrm{T}$ regulatory cells. The tumor necrosis factor receptor family members OX40 (CD134) and 4-1BB (CD137) have been found to play a role in controlling the generation and activity of $\mathrm{T}$ regulatory cells (reviewed in [5]). The activation, expansion, and survival of regulatory $\mathrm{T}$ cells as well as the expression of their suppressive capacities result from distinct signaling pathways involving various membrane receptors and cytokines. Previously, it was concluded that naturally occurring Treg cells mediate suppression in a cell contact dependent, a cytokine-independent mechanism. However, it is highly likely that the suppression mechanisms of Tregs can be divided into: suppression by inhibitory cytokines, suppression by cytolysis, suppression by metabolic disruption and suppression by modulation of dendritic cells (reviewed in [2]). Recently it has been demonstrated that Tregs are able to mediate suppression across a permeable membrane [6]. This phenomenon was mediated by IL-35 and IL-10. The contribution of Treg-derived cytokines in autoimmunity remains controversial but it is possible that $\mathrm{T}$ regulatory cell-derived cytokines can suppress $\mathrm{Th}_{1}$ and/or $\mathrm{Th}_{2}$-type responses and in this manner influence the immune balance. Additionally, it was demonstrated that Tregs have cytolytic capacity and granzyme/perforin pathways are required for this activity [7].

The experimental and clinical aspects of the role of Tregs in the pathogenesis of T1DM have been intensively discussed (reviews in [8] and [9]). Most of the tests were performed on animal models including non- obese diabetic mice (NOD mice) and they report quantitative and/or qualitative disturbances in $\mathrm{T}$ regulatory cells as a crucial factor for development or cure of autoimmune diabetes. However, several fundamental questions concerning the role of Treg cells in the T1DM pathogenesis remain unanswered e.g. previous studies concerned $\mathrm{CD} 4{ }^{+} \mathrm{CD} 25^{+}$not $\mathrm{CD} 127^{\text {low }}$ cells, due to methodological problems only few molecules/cytokines in one sample were assessed etc. Results from other laboratories and our preliminary experiments suggest that $T$ regulatory cells produce cytokines in human organism but the knowledge in this field is poor. The aim of our study was to test the hypothesis that $\mathrm{T}$ regulatory cells express pro- and anti-inflammatory cytokines, elements of cytotoxicity and OX40/4-1BB molecules. In the $\mathrm{CD}^{+}$ $\mathrm{CD} 25^{+} \mathrm{CD} 127 \mathrm{dim} /-$ cells separated from the peripheral blood of children with type 1 diabetes and healthy subjects we found mRNA for TGF- $\beta$, IL-2, IL-4, IL-10, TNF- $\alpha$, OX40, 4-1BB, perforin 1 but not granzyme B.

\section{Materials and methods}

Patients. The examined group consisted of 50 children with T1DM. Fifty two healthy individuals (control group) were enrolled into the study. The subjects from the control group had no signs of autoimmune, chronic, inflammatory, neoplasmatic disease and had negative family history for T1DM (no differences in sex and age compared to the examined group, $\mathrm{p}>0.05$ ), these children did not receive any drugs. Type 1 diabetes in the examined group was diagnosed according to the American Diabetes Association criteria [10]. The mean age of children with T1DM was $10.4 \pm 3.9$ comparing to the controls: $11.0 \pm 3.7$, the mean insulin intake at the moment of blood collection in examined group was $0.9 \mathrm{U} / \mathrm{kg} /$ day, in control subjects -0 . All examined patients were treated only with insulin (intensive regimen), no other drugs were administered in this group. Only children with good clinical status at the admittance to the hospital and no presence of allergy and/or infection or any other chronic disease were enrolled into the study. The peripheral blood was collected after achieving the metabolic balance, 24 to 35 days from the diagnosis/start of insulin treatment. The blood were obtained samples from the patients and controls under the protocols approved by the Medical University of Bialystok institutional review board. An informed consent was given by the participating children and their parents.

Flow cytometry. Mononuclear cells were isolated on Ficoll density gradients. A flow cytometric analysis of T-cell subpopulations was performed using the following markers: anti-CD3 (phycoerythrin-cyanin 5 PECy5 conjugated, UCHT1 clone), anti-CD4 (phycoerythrin-cyanin 7 PECy7 conjugated, SFCI12T4D11 clone or phycoerythrin-cyanin 5 PECy5 conjugated, UCHT1 clone), antiCD25 (fluorescein isothiocyanate FITC conjugated, B1.49.9 clone or ECD conjugated, B1.49.9 clone), anti-CD127 (=IL-7R, phycoerythrin conjugated PE, R34.34 clone), anti-CD134 (=OX40, PE, Ber-ACT35 clone or FITC, ACT35) and anti-CD137 (=4-1BB, PE conjugated, C65-485) purchased from Beckman Coulter and Becton Dickinson (USA). Respective isotype control antibodies were used. The samples were analysed by five-colour flow cytometer Beckman Cytomics FC 500 MPL using CXP software ver 2.0 (Beckman Coulter, USA). A minimum of $10^{5}$ events was aquired for each analysis. The percentages of positive cells were calculated. To determine absolute cell counts, a small volume of blood was 
analyzed for complete blood count (CBC) with a differential. The absolute counts were determined by multiplying the frequency of positive cells determined in cytometric analysis by the number of lymphocytes $[\mathrm{G} / 1]$ as determined by $\mathrm{CBC}$.

Cell separation. $\mathrm{T}$ regulatory cells were isolated from mononuclear cells according to the producer instruction (Miltenyi Biotec, Germany). Briefly, the isolation was performed in a two-step procedure. Firstly, non-CD4 ${ }^{+}$and $\mathrm{CD} 127^{\text {high }}$ cells were indirectly magnetically labelled with a cocktail of antibodies and beads. The labeled cells were subsequently depleted by separation over a MACS column. Secondly, CD $4{ }^{+} \mathrm{CD} 25^{+} \mathrm{CD} 127 \mathrm{dim} /-$ cells were directly labelled with the beads and isolated by positive selection from pre-enriched $\mathrm{CD}^{+}$fraction. To increase the purity, the cells were separated over a second (new) column.

RNA extraction and cDNA synthesis. A total RNA from T regulatory cells $\left(\mathrm{CD} 4{ }^{+} \mathrm{CD} 25^{+} \mathrm{CD} 127 \mathrm{dim} /-\right)$ was isolated and purified using Rneasy Mini Kit (Qiagen) following the manufacturer's protocol. RNA integrity was verified by $1.5 \%$ agarose gel electrophoresis/ethidinum bromide staining and OD 260/280 absorption ratio $>1.95$. One microgram of total RNA was used to prepare cDNA. cDNA synthesis was performed using SuperScript ${ }^{\mathrm{TM}}$ FirstStrand Synthesis System for RT-PCR (Invitrogen) according to manufacturer's instructions in the MJ Research Thermal Cycler (Model PTC-200, Watertown, MA, USA).

Real-time RT-PCR. mRNA levels for transcription factor FoxP3, pro- and anti-inflammatory cytokines (interferon gamma, interleukin-2, interleukin-4, interleukin-10, transforming growth factor $\beta 1$ and tumor necrosis factor $\alpha$ ), activatory molecules (OX40=CD134, 4-1BB=CD137) and elements of cytotoxicity (granzyme B, perforin 1) were determined by real-time PCR technique with the TaqMan chemistry using ready-to-use Low Density Arrays for Gene Expression by Applied Biosystems (www.appliedbiosystems.com). It contained target-specific primers and probe and TaqMan Universal Master Mix, containing AmpErase uracil-N-glycosylase (UNG) to prevent the re-amplification of carryover PCR products. The PCR amplification and fluorescence data collection were performed with ABI PRISM 7900HT Sequence Detection System (Applied Biosystems). To normalize the amount of expressed molecules mRNA, the internal housekeping gene GAPDH was used and each complementary DNA (cDNA) product was tested in quadruplicates for each of the molecules mRNA and GAPDH mRNA. To calculate our data we used Comparative $C_{t}$ method for relative quantification $\left({ }^{\Delta \Delta} C_{t}\right.$ method) which describes the change in expression of the target gene in a test sample relative to a calibrator sample and provides accurate comparison between the initial level of template in each sample [11]. Data were analyzed with Sequence Detector System (SDS) software version 2.1 (Applied Biosystems).

Statistical analysis. The results from flow cytometry and real-time RT PCR were entered into the database in Microsoft Access 2007 and after the completion transferred and analysed in Statistica 8.0 for Windows (StatSoft, Poland) and GraphPad Prism 5.0 (GraphPad Software, USA). Due to asymmetric data distribution (Kolmogorov-Smirnov and Shapiro-Wilk tests) non-parametric tests were used. The results in the examined and control group were compared using Mann-Whitney U-test. The correlation between the clinical parameters and flow cytometry/real time PCR results were assessed with Spearman's Rank Correlation Test. Pvalues less than 0.05 were considered as significant. The graphs were prepared in GraphPad Prism 5.0. The data are presented as median in the results section and median and $25^{\text {th }}$ and $75^{\text {th }}$ percentile in figures.

\section{Results}

\section{No alterations in the frequency of $\mathrm{CD}^{+} \mathrm{CD} 25^{\text {high }} \mathrm{CD} 127^{\text {low }}$ cells between diabetic and control children}

The absolute count of white blood cells and lymphocytes in the peripheral blood was similar in both examined and control groups (differences statistically not significant, data not shown). The percentages of $\mathrm{CD} 4{ }^{+} \mathrm{CD} 25^{\text {high }} \mathrm{CD} 127^{\text {low }}$ cells in the peripheral blood of examined children were very low and did not differ between diabetic and control groups: $0.59 \%(0.30$ $0.80) v s .0 .55 \%(0.26-0.97)$ respectively $(\mathrm{p}=0.95)$. In a small series of patients $(\mathrm{n}=10)$ the peripheral blood was also taken at the admittance to the hospital (day 0). We found no differences in the percentages of assessed cell populations between day 0 and day of the scheduled assessment of Tregs in children with diabetes (data not shown).

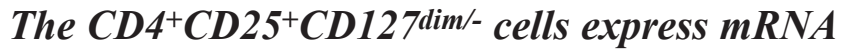 for pro- and anti-inflammatory cytokines}

Concurrently with the flow cytometric assessment of Tregs we separated $\mathrm{CD} 4{ }^{+} \mathrm{CD} 25^{+} \mathrm{CD} 127^{\mathrm{dim} /-}$ cells for further mRNA analysis. FoxP3, IFN- $\gamma$, IL-2, IL-4, IL10 , TNF- $\alpha$, TGF- $\beta 1$, OX 40, $4-1 \mathrm{BB}$ and perforin mRNA presence was confirmed in $100 \%$ of separated $\mathrm{CD} 4{ }^{+} \mathrm{CD} 25^{+} \mathrm{CD} 127 \mathrm{dim} /-$ cells in both control and diabetic children. mRNA for granzyme B was not detected in any of our cell samples. The samples did not differ in mRNA levels of transcription factor Foxp3 between the diabetic and control groups (383 vs. 329 respectively, $\mathrm{p}>0.05$ ). Similarly, the mRNA amounts for cytokines: IFN- $\gamma$, IL-10, IL-2 and TNF- $\alpha$ did not alter in diabetic children compared to the healthy subjects (505.4 vs. 555.8, 218.2 vs. 222.3, 1146 vs. 1577 and $3.70 v s .2 .96$ respectively, $\mathrm{p}>0.05$ ). Interestingly, the expression of mRNA for perforin and TGF- $\beta_{1}$ were higher in examined group in comparison to the controls $(17.71$ vs. $10.39, p=0.006 ; 2.45$ vs. 1.74 , $\mathrm{p}<0.0001$, respectively). The summary of the results obtained from real-time PCR are depicted in Figure 1.

\section{Lower $O X 40$ and higher 4-1BB $m R N A$ but not protein levels in $\mathrm{CD}^{+} \mathrm{CD} 25^{+} \mathrm{CD} 127 \mathrm{dim} /-$ cells in diabetic patients compared to the healthy children}

The example of the results obtained from flow cytometry is shown in Figure 2. We did not find the differences in the percentages of $\mathrm{CD} 4{ }^{+} \mathrm{CD} 25^{\text {high }} \mathrm{CD} 127^{\text {low }}$ $\mathrm{CD}_{134}{ }^{+}$and $\mathrm{CD}^{+} \mathrm{CD} 25^{\text {high }} \mathrm{CD} 137^{+}$cells between examined groups (control vs. diabetic: 0.1 vs. $0.09 \%$ and 0.55 vs. $0.50 \%$ respectively, $\mathrm{p}>0.05$ ) - see Figure 3 . However, the level of mRNA for OX40 was lower 
W. Luczyński et al.

IFN-gamma

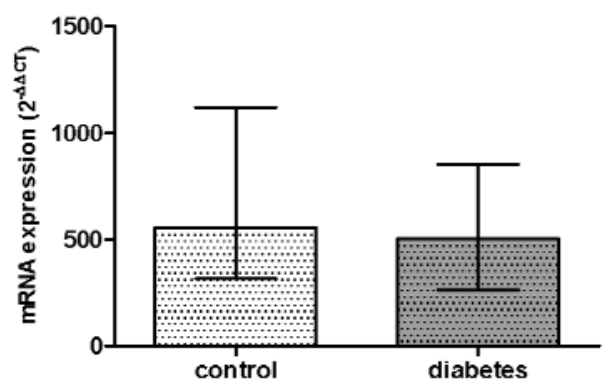

IL-2

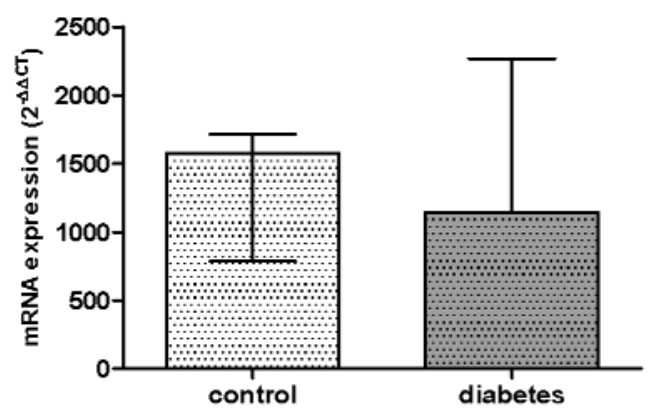

TGF-beta1
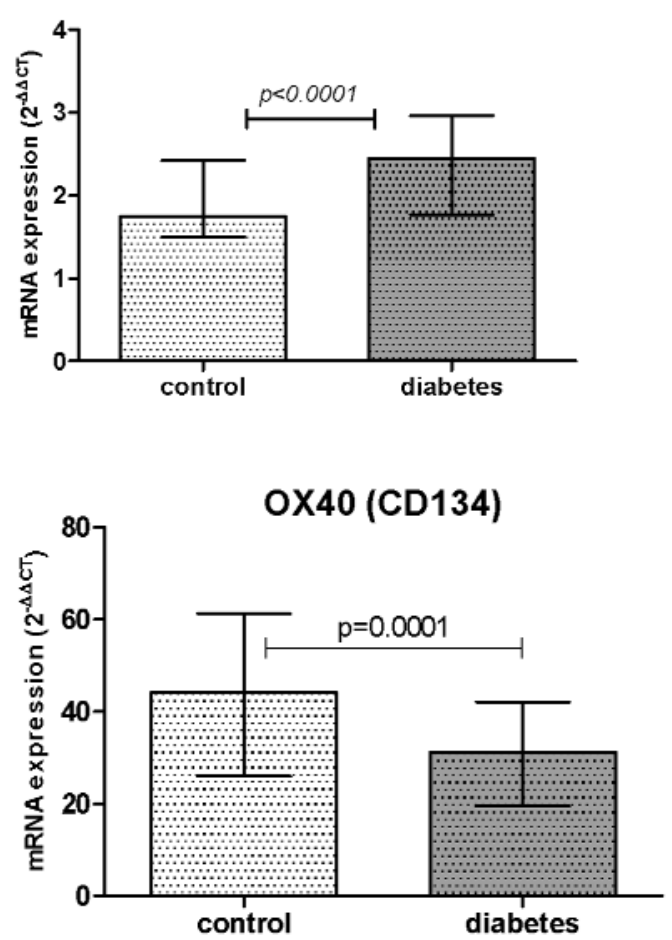

IL-10

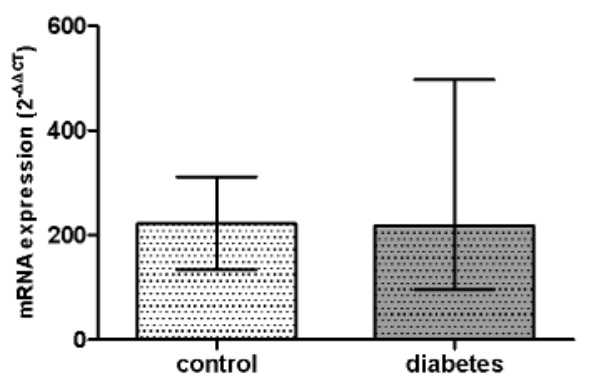

Perforin

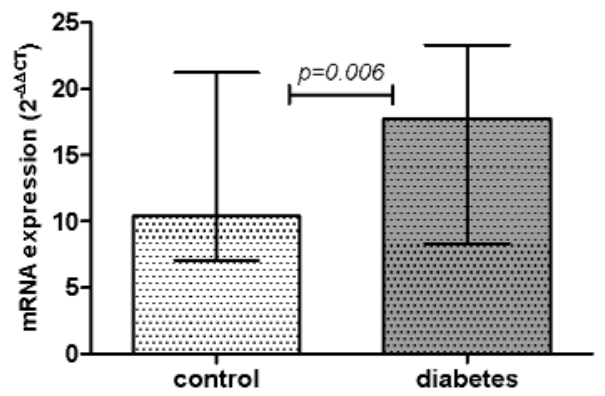

TNF-alfa

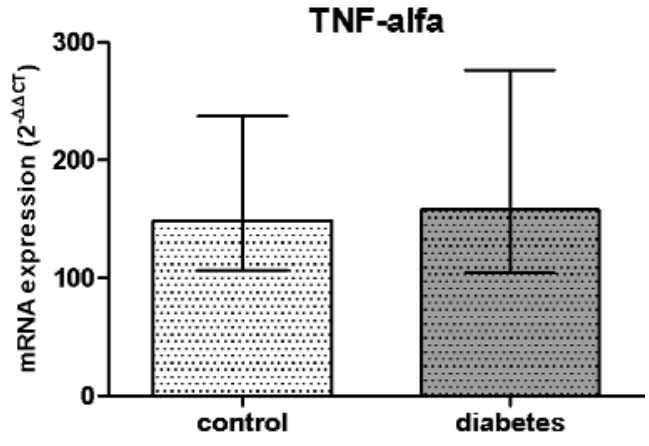

4-1BB (CD137)

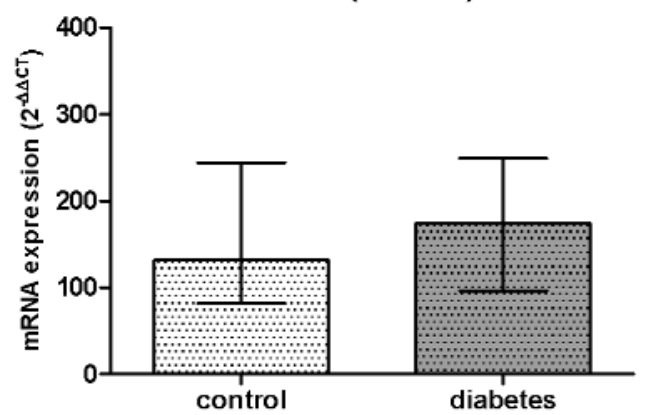

Fig. 1. mRNA expression analysis of chosen genes in CD4+CD25+CD127dim/- cells in children with type 1 diabetes and healthy subjects. Data are presented as median and 25th-75th percentile. The results from real-time PCR showed: higher mRNA levels of perforin and TGF- $\beta 1$, lower amounts of mRNA for OX40 and no differences in IFN- $\gamma$, IL-10, IL-2 and TNF- $\alpha$ expression in separated cells from peripheral blood of children with diabetes compared to control children. Additionally, 4-1BB mRNA expression tended to be higher in examined group but the difference was not statistically significant.

in Treg cells of children with T1DM when compared to the reference patients (31.26 vs. $44.17, \mathrm{p}=0.0001)$. The 4-1BB expression tended to be higher in diabetic children compared with control subjects but the difference was not statistically significant (173.8 vs. 131.5, $\mathrm{p}=0.1$ ). 


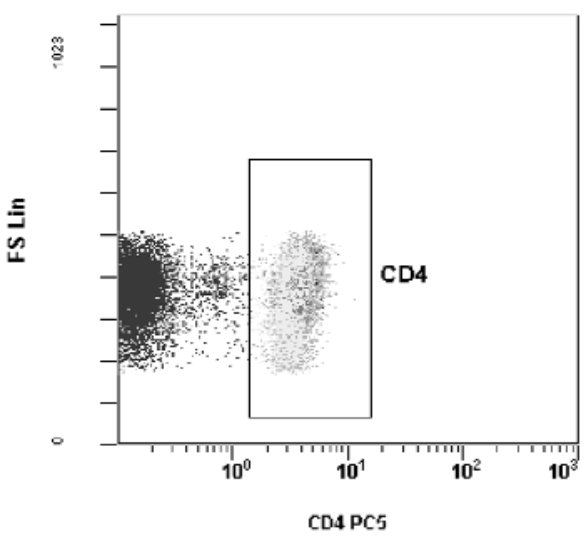

$\mathrm{CD}^{+}$cells $=\mathbf{3 5 . 5} \%$

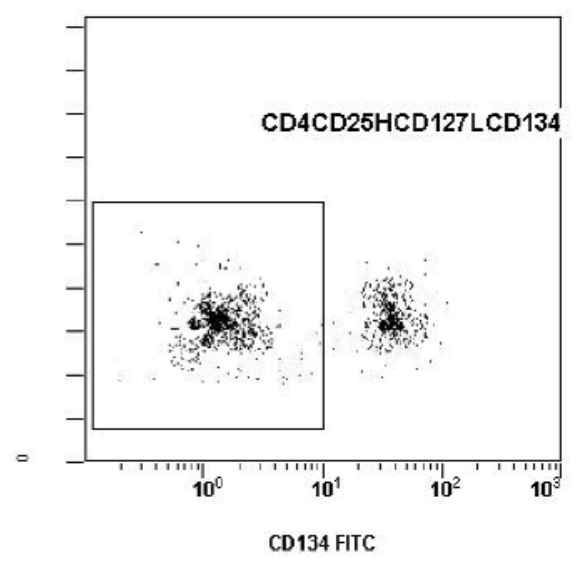

$\mathrm{CD}^{+}{ }^{+} \mathrm{CD} 25^{\text {high }} \mathrm{CD} 127^{\text {low }} \mathrm{CD} 134^{+}$cells $=0.1 \%$
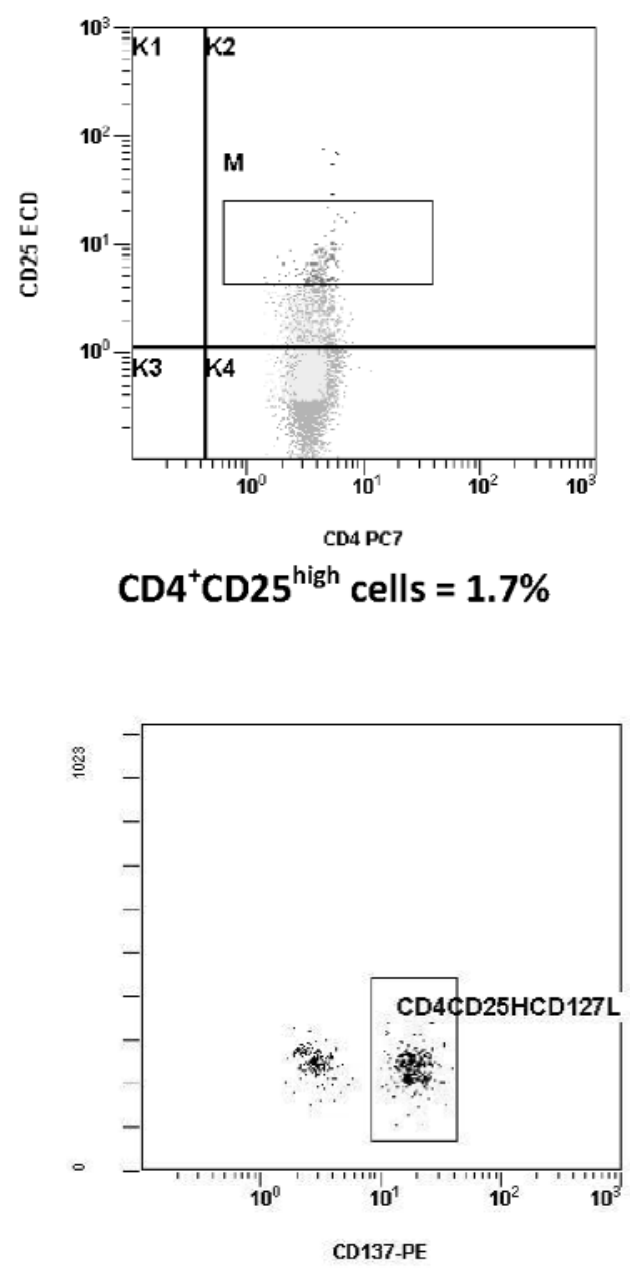

$\mathrm{CD}^{+}{ }^{+} \mathrm{CD} 25^{\text {high }} \mathrm{CD} 137^{+}$cells $=0.3 \%$

Fig. 2. The example of flow cytometry result showing the percentages of $\mathrm{T}$ cell subsets i.e.: $\mathrm{CD} 4^{+}, \mathrm{CD} 4^{+} \mathrm{CD} 25^{\text {high }}, \mathrm{CD} 4^{+} \mathrm{CD} 25^{\text {high }} \mathrm{CD} 134^{+}$and $\mathrm{CD} 4{ }^{+} \mathrm{CD} 25^{\text {high }} \mathrm{CD} 137^{+}$cells. Peripheral blood mononuclear cells were stained with anti-CD4, anti-CD25, anti-CD134 and anti-CD137 antibodies and analyzed by Beckman Cytomics FC 500 MPL. The results are shown as the percentages from total lymphocyte population.

\section{CD4+/CD25high/CD127low/CD134+}

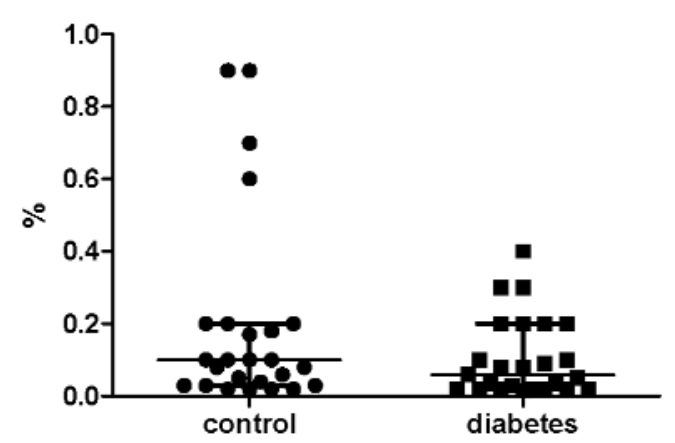

\section{CD4+/CD25high/CD137+}

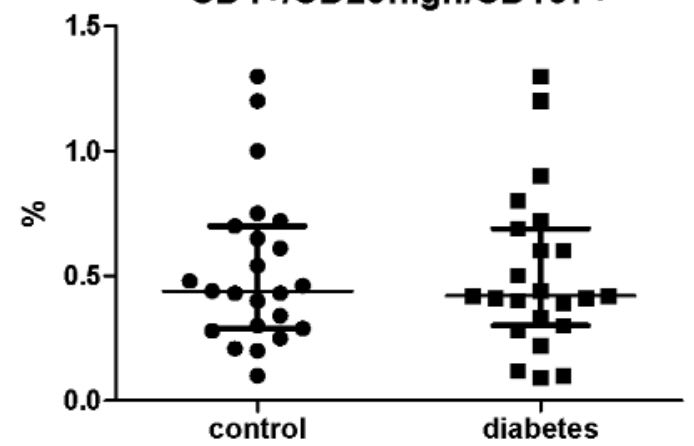

Fig. 3. Frequency of $\mathrm{CD} 4{ }^{+} \mathrm{CD} 25^{\text {high }} \mathrm{CD} 134^{+}$and $\mathrm{CD} 4{ }^{+} \mathrm{CD} 25^{\text {high }} \mathrm{CD} 137^{+}$cells in the control and diabetic patients. Data are presented as scatter plots, median and $25^{\text {th }}-75^{\text {th }}$ percentile.

\section{Discussion}

To test the hypothesis that $\mathrm{T}$ regulatory cells produce pro- and anti-inflammatory cytokines we separated
$\mathrm{CD} 4{ }^{+} \mathrm{CD} 25^{+} \mathrm{CD} 127 \mathrm{dim} /-$ cells from the peripheral blood of healthy and diabetic children. We found the mRNA expression not only for TGF- $\beta$, IL-10 but also for IFN- $\gamma$, IL-2, IL-4 and TNF- $\alpha$. Numerous studies 
over the past few years have demonstrated the importance of naturally occurring $\mathrm{CD} 4^{+} \mathrm{CD} 25^{+} \mathrm{FoxP}^{+}$regulatory $\mathrm{T}$ cells in autoimmune diabetes. To date, results obtained from these experiments are contradictory. Most studies performed on human showed no differences in the percentages of $\mathrm{T}$ regulatory cells between diabetic and healthy subjects. These experiments included the $\mathrm{CD} 4{ }^{+} \mathrm{CD} 25^{\text {high }} \mathrm{CD} 127^{\text {low }}$ and $\mathrm{CD} 4{ }^{+}$ CD25 highFoxP3 ${ }^{+}$cells $[3,12]$. Our results showing similar percentages of Tregs cells and FoxP3 expression in diabetic and control children are in harmony with these findings. Recently, there has been also a great scientific discussion concerning the methodological approach for separating T regulatory cells. Previously $\mathrm{CD} 4{ }^{+} \mathrm{CD} 25^{+}$or $\mathrm{CD} 4{ }^{+} \mathrm{CD} 25^{\text {high }}$ cells were separated for functional evaluation. After few reports which showed that $\mathrm{T}$ regulatory cells present downregulation of IL-7 receptor (CD127) we chose a novel kit from Miltenyi Biotec for separation of $\mathrm{CD} 4{ }^{+} \mathrm{CD} 25^{+} \mathrm{CD} 127 \mathrm{dim} /-$ cells for mRNA analysis. This method allows to assess expression of many genes in one small sample. On the other hand, our results are difficult to compare with the results obtained by other authors.

Our results demonstrated higher expression of mRNA for TGF- $\beta$ in Tregs separated from diabetic children compared to control subjects. The observations of other authors show an important role of TGF$\beta$ and IL-10 production as mediators of Treg activity. The belief that Tregs act in a contact-dependent, cytokine-independent manner was based on studies performed with the use of permeable membrane. Recently Collison et al. showed that the induction of suppression of Tregs was contact-dependent but the function of Tregs was mediated by cytokines: IL-35 and IL-10 [6]. These results raise the possibility of IL10 and IL-35 cooperation for achieving the Treg suppressive activity. It is also possible that pro- and antiinflammatory cytokines produced by $\mathrm{T}$ regulatory cells interfere with $\mathrm{Th}_{1} / \mathrm{Th}_{2}$ polarization towards antigen presenting cells. One of these cytokines is probably TGF- $\beta$ [13].

A novel type of T regulatory cells which possesses a FoxP $3{ }^{+} \mathrm{CD} 4{ }^{+} \mathrm{CD} 8{ }^{+} \mathrm{CD} 25^{+}$phenotype activated by IL-2 produces high levels of IL-10 [14]. These cells have also cytotoxic activities. This may be a newly discovered, additional regulatory mechanism. However mRNA samples in our experiment were $\mathrm{CD}^{+}$negative. In another study the percentages of T cells $\left(\mathrm{CD}^{+}\right)$ producing IL-10 were higher in the peripheral blood of patients with T1DM than in healthy individuals [15].

Surprisingly, we also found in Tregs the mRNA for pro-inflammatory cytokines such as IFN- $\gamma$, IL-2 and TNF- $\alpha$. Interferon gamma can have diverse functions, it mainly induces proinflammatory $\mathrm{Th}_{1}$-type responses, but also enables $\mathrm{T}$ regulatory-type activation.
IFN- $\gamma$ is produced by Tregs and plays a crucial role in their function (reviewed in [16]). Some authors found a strong correlation between expression of FoxP3 and IFN- $\gamma$ in $\mathrm{CD} 4{ }^{+} \mathrm{CD} 25^{+}$cells for example in patients after kidney transplantation [17]. In contrast to our observations absence of IFN- $\gamma$ production was found in $\mathrm{CD} 4{ }^{+} \mathrm{CD} 25^{\text {high }} \mathrm{CD} 39^{+} \mathrm{T}$ regulatory cells in patients with active tuberculosis [18]. Lindley et al. did not observe any differences between diabetic and healthy subjects in the production of IFN- $\gamma$ and IL-10 by $\mathrm{CD} 4{ }^{+} \mathrm{CD} 25^{+}$subpopulations between diabetic and healthy subjects [19]. IL-2 provides important signals for Treg cells development and for their homeostasis in peripheral immune tissues. IL-2 is also essential for the survival of mature Foxp $3^{+}$regulatory T cells. However, Tregs, are not sure to be the source of this cytokine [20].

It is also possible, as suggested by Collison et al., that interactions between Tregs and other elements of immune response can be mediated by bidirectional: contact- and cytokine-dependent signals [6]. On the other hand a newly discovered subset of $\mathrm{T}$ helper cells, Th17 is thought to play a key role in autoimmunity, orchestrating tissue inflammation, with IL-17 and IL22 as effector cytokines. Based on several observations including their own Awasthi et al. proposed a model of the relation between Tregs and Th17 cells [21]. The most interesting information is that addition of IL-6 to Treg cells convert them into Th17 cells. The presence of proinflammatory cytokines confirmed in our $\mathrm{CD} 4{ }^{+} \mathrm{CD} 25^{+} \mathrm{CD} 127 \mathrm{dim} /-$ samples can represent additional link between Th17 and Treg cells, but this relation is not clear and requires further research.

Most authors agree that OX40 inhibits the suppressive activity of $\mathrm{T}$ regulatory cells [5, 22-24]. Earlier reports indicated only minimal influence of $4-1 \mathrm{BB} / 4-$ 1BBL pathway on the proliferation of Tregs but also noted an essential role in their suppressive function [22]. In two series of experiments OX40 signaling inhibited FoxP3 expression and was regarded as antagonist of $\mathrm{T}$ regulatory cells $[23,24]$. Additionally patients with another autoimmune disease - multiple sclerosis (MS) had lower CD137 expression in Tregs compared with healthy controls [25]. The plasma levels of soluble CD137 were higher in the group with MS than in healthy subjects. The impaired 4-1BB mRNA expression found in our Treg samples can be one of the mechanisms of their dysfunction. In another interesting study Tregs showed up-regulation of the 4-1BB expression in response to IL-2 and soluble 41BB ligand [26]. Additionally treatment with antiCD137 protected NOD mice from diabetes [27]. This phenomenon was probably mediated by $\mathrm{T}$ regulatory cells.

The cytotoxicity, cell contact-independent mechanism including granzyme/perforin may represent one 
of the pathways by which Tregs can induce long-lasting suppression of autoimmune diseases. Little is known about the expression of granzyme/perforin in Treg cells in patients with autoimmune diabetes. One report showed enhancement of $\mathrm{T}$ regulatory cell function including FoxP3 and granzyme B expression by complete Freund's adjuvant (CFA) therapy in nonobese diabetic mice [28]. In another study the differences in the mRNA expression of perforin between control and diabetic patients were not significant, however, according to Gondek et al. the contact-mediated suppression of Tregs is not perforin-dependent [29]. We did not find the mRNA for granzyme B in human Tregs. According to Cao et al. granzyme B is not expressed in naive Tregs but can be found in Tregs present in tumor environment in mice [7]. Some studies concerning cytotoxic function of Tregs were performed in another autoimmune and neoplasmatic diseases. For example our results concerning low/negative expression of granzyme B are in agreement with recent findings in human ulcerative colitis and some neoplasmatic diseases [30].

Our results and other authors' observations confirm the presence of mRNA for pro- and anti-inflammatory cytokines in $\mathrm{CD} 4{ }^{+} \mathrm{CD} 25^{+} \mathrm{CD} 127 \mathrm{dim} /-$ cells in the peripheral blood of children with T1DM. Further studies with the goal of developing new strategies to potentiate Treg function in autoimmune diseases are warranted. It would be also of clinical significance if Treg cells were used not only in a autoimmune-prone individuals but also in established disease like newly recognised diabetes.

\section{Conclusions}

We found mRNA for pro- and anti-inflammatory cytokines in $\mathrm{CD} 4{ }^{+} \mathrm{CD} 25^{+} \mathrm{CD} 127 \mathrm{dim} /-$ cells in the peripheral blood of children with type 1 diabetes. We also observed lower mRNA expression for OX40 in these cells but not at protein level compared to healthy children.

Perhaps the best approach for immunotherapeutic intervention in T1DM is to identify and expand antigen-specific Tregs and re-infuse these cells into the patient. If this approach is to be introduced, the function of Tregs in autoimmune diseases should be elucidated. Our and other authors' findings add some supplementary information to a debate about preclinical studies concerning $\mathrm{T}$ regulatory cells in autoimmune diseases. Further examination of the role of cytokine production and expression of OX40 and 4-1BB by Treg cells in diabetes might be warranted.

\section{References}

[ 1] Sakaguchi S, Sakaguchi N, Asano M, Itoh M, Toda M. Immunologic self-tolerance maintained by activated $\mathrm{T}$ cells expressing IL-2 receptor alpha-chains (CD25). Breakdown of a single mechanism of self-tolerance causes various autoimmune diseases. J Immunol. 1995;155:1151-1164.

[2] Vignali DA, Collison LW, Workman CJ. How regulatory T cells work. Nat Rev Immunol. 2008;8:523-532.

[3] Liu W, Putnam AL, Xu-Yu Z et al. CD127 expression inversely correlates with FoxP3 and suppressive function of human CD4 ${ }^{+}$T reg cells. J Exp Med. 2006;203:1701-1711.

[ 4] Seddiki N, Santner-Nanan B, Martinson J et al. Expression of interleukin (IL)-2 and IL-7 receptors discriminates between human regulatory and activated $\mathrm{T}$ cells. J Exp Med. 2006;203:1693-1700.

[5] So T, Lee SW, Croft M. Immune regulation and control of regulatory T cells by $\mathrm{OX} 40$ and 4-1BB. Cytokine Growth Factor Rev. 2008;19:253-262.

[ 6] Collison LW, Pillai MR, Chaturvedi V, Vignali DA. Regulatory $\mathrm{T}$ cell suppression is potentiated by target $\mathrm{T}$ cells in a cell contact, IL-35 and IL-10-dependent manner. J Immunol. 2009; 182:6121-6128.

[ 7] Cao X, Cai SF, Fehniger TA et al. Granzyme B and perforin are important for regulatory $\mathrm{T}$ cell-mediated suppression of tumor clearance. Immunity. 2007;27:635-646.

[ 8] Brusko T, Bluestone J. Clinical application of regulatory T cells for treatment of type 1 diabetes and transplantation. Eur J Immunol. 2008;38:931-934.

[9] Bluestone JA, Tang Q, Sedwick CE. T regulatory cells in autoimmune diabetes: past challenges, future prospects. $J$ Clin Immunol. 2008;28:677-684.

[10] Association AD. Diagnosis and classification of diabetes mellitus. Diabetes Care. 2008;31:55-60.

[11] Livak KJ, Schmittgen TD. Analysis of relative gene expression data using real-time quantitative PCR and the 2-ddCT method. Methods. 2001;25:402-408.

[12] Brusko T, Wasserfall C, McGrail K et al. No alterations in the frequency of FoxP3+ regulatory T-cells in type 1 diabetes. Diabetes. 2007;56:604-612.

[13] Esquerre M, Tauzin B, Guiraud M, Muller S, Saoudi A, Valitutti S. Human regulatory $\mathrm{T}$ cells inhibit polarization of $\mathrm{T}$ helper ccells toward antigen-presenting cells via TGF-betadependent mechanism. Proc Natl Acad Sci. 2008;105:25502555 .

[14] Tsuji-Takayama K, Suzuki M, Yamamoto M et al. IL-2 activation of STAT5 enhances production of IL-10 from human cytotoxic regulatory $\mathrm{T}$ cells, HOZOT. Exp Hematol. 2008;36:181-192.

[15] Foss-Freitas MC, Foss NT, Rassi DM, Donadi EA, Foss MC. Evaluation of cytokine production from peripheral blood mononuclear cells of type 1 diabetic patients. Ann N Y Acad Sci. 2008;1150:290-296.

[16] Wood KJ, Sawitzki B. Interferon gamma: a crucial role in the function of induced regulatory $\mathrm{T}$ cells in vivo. Trends Immunol. 2006;27:183-187.

[17] Daniel V, Naujokat C, Sadeghi M et al. Observational support for an immunoregulatory role of $\mathrm{CD}^{+} \mathrm{CD} 4{ }^{+} \mathrm{CD} 25^{+} \mathrm{IFN}$ gamma $^{+}$blood lymphocytes in kidney transplant recipients with good long-term graft outcome. Transplant Int. 2008;21:646-660.

[18] Chiacchio T, Casetti R, Butera O et al. Characterization of regulatory $\mathrm{T}$ cells identified as $\mathrm{CD} 4(+) \mathrm{CD} 25$ (high)CD39(+) in patients with active tuberculosis. Clin Exp Immunol. 2009; 156:463-470.

[19] Lindley S, Dayan CM, Bishop A, Roep BO, Peakman M, Tree TI. Defective suppressor function in CD4(+)CD25(+) Tcells from patients with type 1 diabetes. Diabetes. 2005;54: 92-99.

[20] D'Cruz L, Klein L. Development and function of agonistinduced $\mathrm{CD}_{2} 5^{+} \mathrm{FoxP}_{3}{ }^{+}$regulatory $\mathrm{T}$ cells in the absence of interleukin 2 signalling. Nat Immunol. 2005;6:1152-1159. 
[21] Awasthi A, Murugaiyan G, Kuchroo VK. Interplay between effector Th17 and regulatory $\mathrm{T}$ cells. J Clin Immunol. 2008;28:660-670.

[22] Choi BK, Bae JS, Choi EM et al. 4-1BB-depedent inhibition of immunosuppression by activated $\mathrm{CD} 4{ }^{+} \mathrm{CD} 25^{+} \mathrm{T}$ cells. $J$ Leukoc Biol. 2004;75:785-790.

[23] So T, Croft M. Cutting edge: OX40 inhibits TGF-beta- and antigen-driven conversion of naive CD4 $\mathrm{T}$ cells into CD25+FoxP3 ${ }^{+}$T cells. J Immunol. 2007;179:1427-1430.

[24] Valzasina B, Guiducci C, Dislich H, Killeen N, Weinberg AD, Colombo MP. Triggering of OX40 (CD134) on CD4(+)CD25+ T cells blocks their inhibitory activity: a novel regulatory role for OX40 and its comparison with GITR. Blood. 2005;105:2845-2851.

[25] Liu GZ, Gomes AC, Fang LB, Gao XG, Hjelmstrom P. Decreased $4-1 \mathrm{BB}$ expression on $\mathrm{CD} 4{ }^{+} \mathrm{CD} 25$ high regulatory $\mathrm{T}$ cells in peripheral blood of patients with multiple sclerosis. Clin Exp Immunol. 2008;154:22-29.

[26] Elpek KG, Yolcu ES, Franke DD, Lacelle C, Schabowsky $\mathrm{RH}$, Shirwan H. Ex vivo expansion of $\mathrm{CD} 4^{+} \mathrm{CD} 25^{+} \mathrm{FoxP} 3^{+} \mathrm{T}$ regulatory cells based on synergy between IL-2 and 4-1BB signaling. J Immunol. 2007;179:7295-7304.

[27] Irie J, Wu Y, Kachapati K, Mittler RS, Ridgway WM. Modulating protective and pathogenic $\mathrm{CD}^{+}$subsets via CD137 in type 1 diabetes. Diabetes. 2007;56:186-196.

[28] Manirarora JN, Kosiewicz MM, Parnell SA, Alard P. APC activation restores functional $\mathrm{CD} 4(+) \mathrm{CD} 25(+)$ regulatory T cells in NOD mice that can prevent diabetes development. PLos ONE. 2008;3:e3739.

[29] Gondek DC, Lu LF, Quezada SA, Sakaguchi S, Noelle RJ. Cutting edge: contact-mediated suppression by $\mathrm{CD} 4{ }^{+} \mathrm{CD} 25^{+}$ regulatory cells involves a granzyme B-dependent, perforinindependent mechanism. J Immunol. 2005;174:1783-1786.

[30] Kryczek I, Liu R, Wang G et al. FoxP3 defines regulatory T cells in human tumor and autoimmune disease. Cancer Res. 2009;69:3995-4000.

Submitted: 17 October, 2009 Accepted after reviews: 3 January, 2010 